\title{
Experimental and theoretical study of microwave enhanced catalytic hydrodesulfurization of thiophene in a continuous-flow reactor
}

\author{
Hui Shang $(\bowtie){ }^{1}$, Pengfei Ye ${ }^{1}$, Yude Yue ${ }^{1}$, Tianye Wang ${ }^{1}$, Wenhui Zhang ${ }^{1}$, Sainab Omar ${ }^{2}$, Jiawei Wang $(\bowtie)^{2}$ \\ 1 State Key Laboratory of Heavy Oil Processing, China University of Petroleum (Beijing), Beijing 102249, China \\ 2 European Bioenergy Research Institute, Aston University, Birmingham, B4 7ET, UK
}

(C) The Author(s) 2019. This article is published with open access at link.springer.com and journal.hep.com.cn 2019

\begin{abstract}
Hydrodesulfurization (HDS) of thiophene, as a gasoline model oil, over an industrial $\mathrm{Ni}-\mathrm{Mo} / \mathrm{Al}_{2} \mathrm{O}_{3}$ catalyst was investigated in a continuous system under microwave irradiation. The HDS efficiency was much higher $(5 \%-14 \%)$ under microwave irradiation than conventional heating. It was proved that the reaction was enhanced by both microwave thermal and non-thermal effects. Microwave selective heating caused hot spots inside the catalyst, thus improved the reaction rate. From the analysis of the non-thermal effect, the molecular collisions were significantly increased under microwave irradiation. However, instead of being reduced, the apparent activation energy increased. This may be due to the microwave treatment hindering the adsorption though upright S-bind $\left(\eta^{1}\right)$ and enhancing the parallel adsorption $\left(\eta^{5}\right)$, both adsorptions were considered to favor to the direct desulfurization route and the hydrogenation route respectively. Therefore, the HDS process was considered to proceed along the hydrogenation route under microwave irradiation.
\end{abstract}

Keywords thiophene, microwave irradiation, hydrodesulfurization, non-thermal microwave effect

\section{Introduction}

Due to the growing awareness of environmental protection, new regulations requiring ultralow sulfur concentration in transport fuels have been implemented, and in the near future, global sulfur emissions are expected to reach zero. In China, fluid catalytic cracking (FCC) gasoline is

Received February 25, 2019; accepted March 18, 2019

E-mails: huishang@cup.edu.cn (Shang H),

j.wang23@aston.ac.uk (Wang J) the biggest sulfur contributor (more than $80 \%$ ) of the gasoline products on the market. Therefore, reducing the sulfur content in FCC gasoline would be one of the most effective measures to reduce air pollution and is essential for meeting the environmental requirements. Catalytic hydrodesulfurization (HDS) is a widely used commercial technology for sulfur removal in gasoline. However, the octane-boosting olefins within FCC gasoline are easily hydrogenated during the HDS processes, resulting in a huge loss of octane number $[1,2]$. Thus, highly selective HDS techniques of FCC gasoline are preferred for deep desulfurization and low olefin hydrogenation, which can be achieved by either enhancing HDS processes or developing high efficiency HDS catalysts.

Microwave electromagnetic heating has attracted considerable attention for HDS process enhancement and HDS catalyst synthesis due to its specific heating mechanism [39]. The theory of microwave enhanced chemical reactions were studied by researchers [10-15], and the microwave intensifications have been broadly called as the "microwave effect". Generally, the response of the scientific community was to propose two explanations for microwave effect: rapid heating and temperature gradients within the reactor. Rapid heating can be attributed to the mode of energy transfer. Microwave energy converts to heat through coupling with polar molecules of the workload $[15,16]$. The heating effect is induced by the interaction between the electric field and the charged molecules in the workload. Whilst heat transfer proceeds in the usual way (by heating the surface of the material by radiation, convection conduction or conventional heating), the heating efficiency is limited by the materials' thermal properties. This mode of energy conversion has the advantage of being selective to individual material phases within a large mass and is beneficial for high heating rates. Temperature gradients can also be induced by microwave 
selective heating of polar materials within the catalyst bed, thus due to the uneven heating, the heating rate can be improved in the higher temperature area $[12,13]$. By investigating the HDS process of petroleum streams, researchers found that the operational conditions are less severe and treatment time is shorter with microwave heating compared to conventional heating [7-9]. In microwave heating mechanism, the polarities of the materials (reactants and the transition state materials) present in the reaction system play an important role in the heating rate [10,11]. Zhang et al. [11] found that catalyst particles with more polarity would absorb more microwave energy, inducing hot spots during the reaction. This uneven heating has a significant effect on sulfur conversion. Rodríguez et al. [10] found that beside the polarity, the activation energy and the reaction thermal effect are also key factors, only the reactions with an appropriate activation energy value can be enhanced by microwave heating.

There is limited research concerning the reaction kinetics of HDS under microwave irradiation, which is due to the difficulty in measuring the temperature inside the reaction under microwave irradiation. Consequently, the developed thermal gradients, along with the difficulty in measuring the temperature inside the cavity, can lead to wrong kinetics. Despite this, some scholars $[12,17]$ have been devoted to solve the problems and studied the reaction kinetics. When analyzing the kinetics, Raner et al. [17] used stirring during microwave heating, to elevate the thermal gradients. However the authors considered that microwave dielectric heating does not directly excite the molecule to higher rotational or vibrational energy levels, but the energy absorbed by the material will increase its internal energy, hence suggesting that there is no kinetic differences between microwave irradiated reactions and conventional heated reactions. Raner et al. denied the existance of microwave nonthermal effects. Perry et al. [12] studied the kinetics of the $\mathrm{CO}$ oxidation reaction on $\mathrm{Pt} / \mathrm{Al}_{2} \mathrm{O}_{3}$ under microwave and conventional heatings. They measured the temperature by inserting a thermocouple after the microwaves were switched off. In this study, the kinetic enhancement was also attributed to the temperature gradient.

In general, particular attention should be paid to the design of experiments with complete and certain knowledge of the internal specimen temperature during microwave irradiation. Furthermore, numerical simulations may provide additional insight. In spite of the above information, some researchers support the idea of microwave nonthermal effects [13], assisted by simulation, strong microwave electric fields induce a nonlinear driving force for mass transport of solid materials. This driving force would then influence the reaction kinetics by enhancing mass transport rates in heterogeneous solidstate reactions. Borges et al. [18] investigated the mechanism of microwave assisted HDS of thiophene and proved the existence of hot spots by the simulation method. They calculated the polarizability and the permanent dipole moment of the optimized adsorbed thiophene on $\mathrm{Mo}_{16} \mathrm{~S}_{32}$ cluster, and concluded that the permanent dipole was the main factor for dielectric heating. These findings are very important, however, they were induced from the calculation based on equations, not through the simulation, due to the impossibility of adding alternative electric fields into the simulation. Therefore the results obtained do not accurately reflect the real information of HDS in an electromagnetic field.

Thiophene belongs to the most refractory sulfurcontaining molecules present in FCC gasoline. It is the most difficult sulfur containing molecule to remove due to aromatic stabilization, hence it is often used as a model sulfur compound in research. The HDS mechanisms of thiophene would provide the theory of the catalysis processes, which can then be used to assist in the development of catalysts and the process. There are two pathways for the sulfur removal from thiophene during HDS: hydrogenation (HYD) and direct desulfurization (DDS) (Figs. 1 and 2) [19-22]. However, the mechanism of HDS is highly dependent on the interaction of sulfides and catalysts, it is influenced by many factors such as the sulfur's adsorption position as well as its adsorption state and the sulfur vacancies formed on the catalyst [18,22-26].

In reality, due to the limitation of reactor materials employed in microwave cavity, most desulfurization reactions with microwave irradiation were conducted in batch reactors. The reactor materials were either polytetrafluoroethylene or glass/quartz, which limit the maximum operating temperature and pressure, whereas, the HDS process requires high operating temperature and pressure to achieve very low sulfur content. Furthermore, the theoretical studies are different from the real processes conducted by microwaves as most researchers carried out calculations using the Materials Studio software. However, it is very difficult to investigate the HDS process using microwave electric field through simulation. Therefore, the development of a continuous HDS process and better understanding of the real effects of microwave irradiation on the process are essential for applying microwave assisted HDS on a commercial scale.

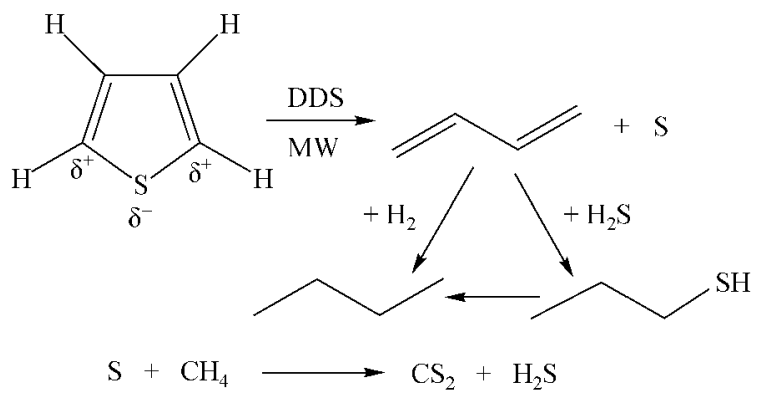

Fig. 1 Microwave induced thiophene direct desulfurization route. 


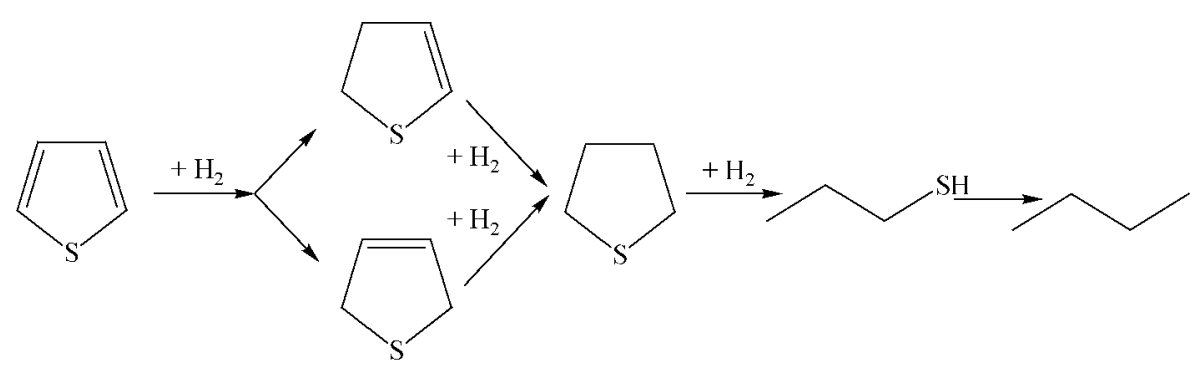

Fig. 2 Thiophene hydrogenation desulfurization route.

To address the above issue we successfully developed a continuous microwave enhanced HDS system. Our previous studies showed that microwave irradiation is an efficient technology for HDS of gasoline, and the HDS ratio can be highly enhanced by the applied electromagnetic field [27-32]. However, the critical aspects of how microwave enhances the catalytic HDS have not been elucidated yet. In this paper, we investigated the role of microwave irradiation in the continuous catalytic HDS of thiophene over a commercial $\mathrm{Ni}-\mathrm{Mo} / \mathrm{Al}_{2} \mathrm{O}_{3}$ catalyst by experimental and theoretical studies. The study also aimed to understand the reaction pathways and mechanisms of catalytic HDS reactions under microwave irradiation.

\section{Materials and methods}

\subsection{Materials}

The gasoline model oil was prepared using thiophene as the sulfur model compound. Thiophene was added into a mixture of cyclohexane (20 wt- $\%)$, toluene (5 wt- $\%)$, 1-hexane (5 wt- $\%)$ and $n$-heptane (70 wt- $\%)$. The sulfur content of the model oil was in the range of 200 $280 \mu \mathrm{g} \cdot \mathrm{mL}^{-1}$.

A Ni-Mo/ $/ \mathrm{Al}_{2} \mathrm{O}_{3}$ commercial HDS catalyst was used, with $\mathrm{NiO}$ and $\mathrm{MoO}_{2}$ of $3 \mathrm{wt}-\%$ and $15 \mathrm{wt}-\%$, respectively. The catalyst had a surface area of $168 \mathrm{~m}^{2} \cdot \mathrm{g}^{-1}$. In all runs, the catalysts were pre-sulfurized in situ at $340^{\circ} \mathrm{C}, 2 \mathrm{MPa}$ for $4 \mathrm{~h}$ by passing a stream containing $3 \mathrm{wt}-\% \mathrm{CS}_{2}$ in cyclohexane through the catalyst bed in the presence of pure $\mathrm{H}_{2}$. Hydrogen gas used in this study was obtained from a cylinder with an ultra-high purity grade (99.99\%).

\subsection{Microwave continuous HDS device and process}

The microwave assisted HDS experiments were carried out in a continuous-flow fixed-bed reactor loaded with $15 \mathrm{~g}$ catalyst. In order to eliminate the resistance of internal and external diffusion, the influence of the catalyst particle size as well as its loaded amount were investigated in our previous work. This demonstrated that 40-60 mesh particle size with the amount of $15 \mathrm{~g}$ can prevent the resistance of internal and external diffusion, thus improving the heat and mass transfer during the reaction. A $0-3$ $\mathrm{kW}$ microwave generator (2.45 GHz) was used (Fig. 3). The microwave cavity was designed by our research group based on electromagnetic field distribution and the properties of the workload, and was used as the HDS reactor directly. The reactor has a diameter of $40 \mathrm{~mm}$ and a height of $300 \mathrm{~mm}$. Microwave energy was introduced into the applicator through waveguides, on line power meters were used to measure the forward and reflected power during reaction. For comparison, a series of HDS experiments with a conventional heating were carried out using an identical reactor. The operated hydrogen/oil ratio of 200:1 (v/v) and weight hourly space velocity (WHSV) of $2 \mathrm{~h}^{-1}$ and various microwave power levels were required at different temperatures.

The catalyst was diluted with quartz sand and silica carbide to a constant volume of $30 \mathrm{~mL}$ before being loaded into the reactor. Silica carbide was used as a microwave absorber. The volume ratio of silicon carbide, catalyst, and quartz sand were $3: 5: 2$, respectively. The aim of the dilution was to keep the height of the reaction zoon, therefore WHSV here is based only on the real amount of the catalyst. Nitrogen gas was applied for reinforcing pressure after sampling and leakage tests. After the pressure reduction valve, the hydrogen gas was mixed with the model oil, which was pumped from an oil container, through a T-valve and then introduced into the reactor. Preheating was conducted to a desired temperature after a leakage test. Microwave energy was subsequently introduced into the reactor. Finally, the reaction was carried out under certain conditions. After a stabilization period of $8 \mathrm{~h}$, the products were collected and identified.

\subsection{Catalytic performance evaluation}

The total sulfur contents were measured via a sulfur and nitrogen analyzer (RPP-2000SN, Taizhou Central Analytical Instruments Co. Ltd., China). The liquid products were analyzed using a gas chromatography mass spectrometry (GC-MS, Thermo-Finnigan Trace DSQ) with a HP$5 \mathrm{MS}$ column $(60 \mathrm{~m} \times 0.25 \mathrm{~mm} \times 0.25 \mu \mathrm{m})$.

The hydrocarbons compositions of the feedstock 


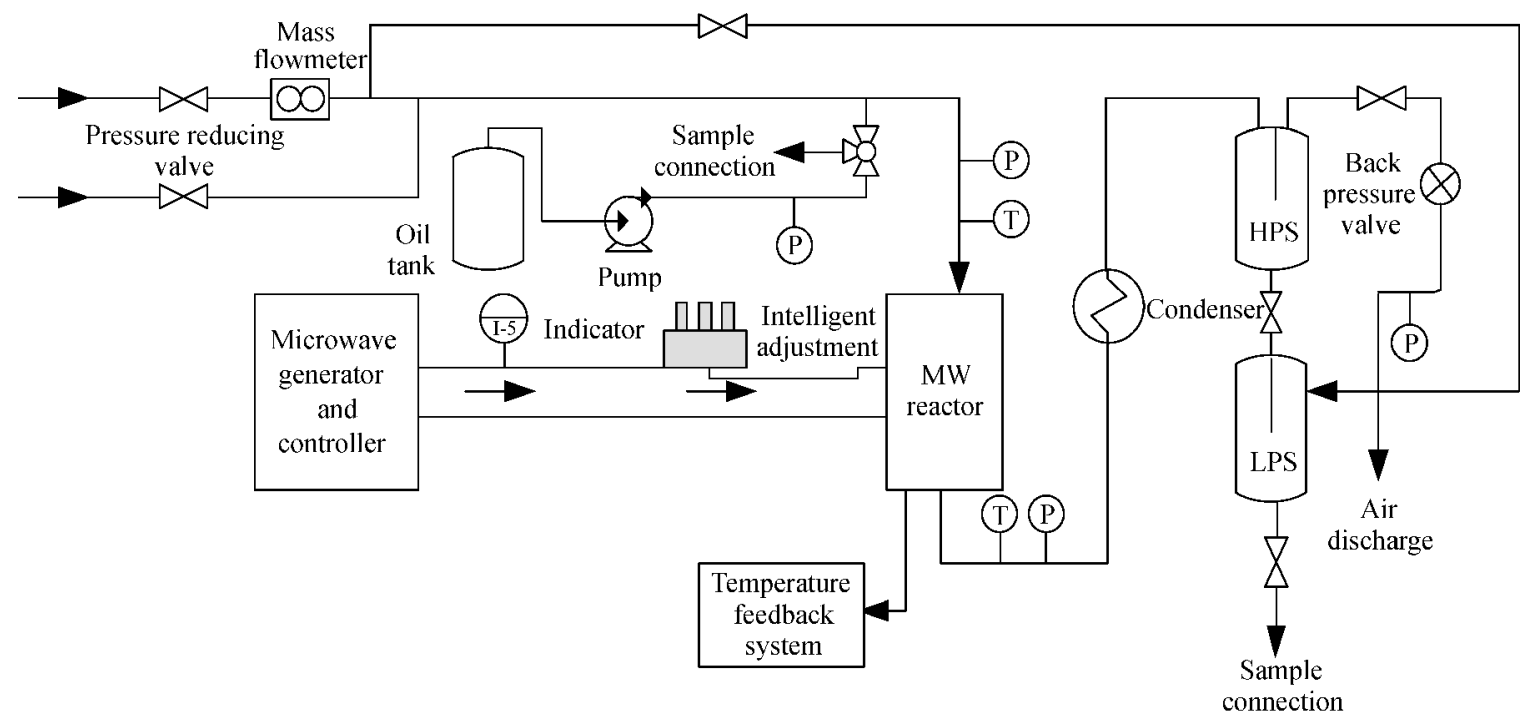

Fig. 3 The continuous microwave hydrodesulfurization reaction device. HPS: high pressure separator; LPS: low pressure separator.

and products were determined with a SP-3420 gas chromatograph installed with a flame ionization detector and a PONA (Paraffin, Olefin, Naphthene, Aromatics) capillary column $(50 \mathrm{~m} \times 0.2 \mathrm{~mm} \times 0.5 \mu \mathrm{m})$. The efficiency of sulfur removal, HDS ratio, was calculated by the Eq. (1):

$$
\text { HDS Ratio }=\frac{S_{\mathrm{f}}-S_{\mathrm{p}}}{S_{\mathrm{f}}} \times 100 \%,
$$

where $S_{\mathrm{f}}$ and $S_{\mathrm{p}}$ are the total sulfur contents of the feedstock and product in mass fraction, respectively.

Temperature measurement is considered difficult inside a microwave cavity due to the interference of the electromagnetic field with the metallic thermocouples. In this study, the relationship between outlet temperature and temperature in the middle of the reactor was determined via conventional heating. Based on the data, nonlinear fitting was adopted and the following equation was achieved with $R^{2}$ value of 0.994 .

$$
y=0.00535 \times x^{2}+0.55504 \times x+20.5183 .
$$

This data was then used to apply a correction factor for the temperature measurement during microwave heating, and the error was found to be $\pm 0.8^{\circ} \mathrm{C}$. Since there may be hot spots inside the reaction system, which is hardly to measure, the temperature distribution within microwave cavity was then simulated.

\subsection{Simulation of electromagnetic field and temperature distribution}

The simulation was conducted via coupling of two physics phenomena-electromagnetism and heat transfer through COMSOL software as we stated in our former paper [33]. Electric field distribution in a microwave heating cavity was based on solving Maxwell's equations.

$$
\nabla \times\left(\frac{1}{\mu^{\prime}} \nabla \times \overrightarrow{\mathrm{E}}\right)-\frac{\omega^{2}}{c}\left(\varepsilon^{\prime}-i \varepsilon^{\prime \prime}\right) \overrightarrow{\mathrm{E}}=0,
$$

where $\vec{E}$ is electric field intensity $\left(\mathrm{V} \cdot \mathrm{m}^{-1}\right), \varepsilon^{\prime}$ is relative permittivity or dielectric constant of a material, $\varepsilon^{\prime \prime}$ is relative dielectric loss, $\omega$ is angular wave frequency ( $2 \pi f$, $\left.\mathrm{rad} \cdot \mathrm{s}^{-1}\right), \mu^{\prime}$ is the relative permeability and $c$ is the speed of light in free space $\left(3 \times 10^{8} \mathrm{~m} \cdot \mathrm{s}^{-1}\right)$. The heat generation in dielectric materials by microwave radiation can be achieved through Eq. (4).

$$
Q=\sigma|\overrightarrow{\mathrm{E}}|^{2}=2 \pi \varepsilon_{0} \varepsilon^{\prime \prime} f|\overrightarrow{\mathrm{E}}|^{2},
$$

where $\sigma$ is the electrical conductivity of the material $\left(\mathrm{S} \cdot \mathrm{m}^{-1}\right), \varepsilon_{0}$ is free space permittivity $\left(8.854 \times 10^{-12}\right.$ $\left.\mathrm{F} \cdot \mathrm{m}^{-1}\right)$, and $f$ is the employed frequency $(\mathrm{Hz})$. The heat transfer process can be obtained via Fourier's energy balance equation (Eq. (5)).

$$
\frac{\partial T}{\partial t}+\vec{\nu} \nabla T=\frac{\kappa}{\rho C_{\mathrm{p}}} \nabla^{2} T+\frac{Q}{\rho C_{\mathrm{p}}},
$$

where $\rho$ : material density $\left(\mathrm{kg} \cdot \mathrm{m}^{-3}\right), C_{\mathrm{p}}$ : specific heat $\left(\mathrm{J} \cdot \mathrm{kg}^{-1} \cdot \mathrm{K}^{-1}\right), \quad \kappa$ : thermal conductivity $\left(\mathrm{W} \cdot \mathrm{m}^{-1} \cdot \mathrm{K}^{-1}\right)$, $T$ : temperature $(\mathrm{K}), \vec{\nu}$ : velocity vector $\left(\mathrm{m} \cdot \mathrm{s}^{-1}\right)$ and $Q$ : the volumetric heat generation due to the incident microwave energy $\left(\mathrm{W} \cdot \mathrm{m}^{-3}\right)$. As the result of Eq. (3), $Q$ is the heat source of material acting as a bridge between electromagnetism and heat transfer. Temperature distribution due to heat conduction and convection can be obtained from Eq. (5). Fluid flow should be considered in a continuous reaction system, which was governed by Navier-Stokes equation (Eq. (6) and Eq. (7)), which describe the momentum balance and 
continuity.

$$
\begin{gathered}
\rho \frac{\partial \vec{\nu}}{\partial t}=-\nabla P+\mu \nabla^{2} \vec{\nu}+\rho g, \\
\nabla \cdot \vec{\nu}=0,
\end{gathered}
$$

where $\nabla P$ : the pressure difference $(\mathrm{Pa}), g$ : the acceleration due to gravity $\left(\mathrm{m} \cdot \mathrm{s}^{-2}\right)$, and $\mu$ : the fluid's viscosity $(\mathrm{Pa} \cdot \mathrm{s})$.

The reactor model was established using COMSOL,
Fig. 4 Shows the model and the meshing result. Based on the above governing equations, microwave heating module together with the Fluid Flow module were applied to the device for the continuous reaction system.

\subsection{Molecular simulation}

The dipole moment and band order were calculated using $\mathrm{Dmol}^{3}$ of Materials Studio software. The revised PerdewBurke-Ernzerhof (RPBE) function was selected from the
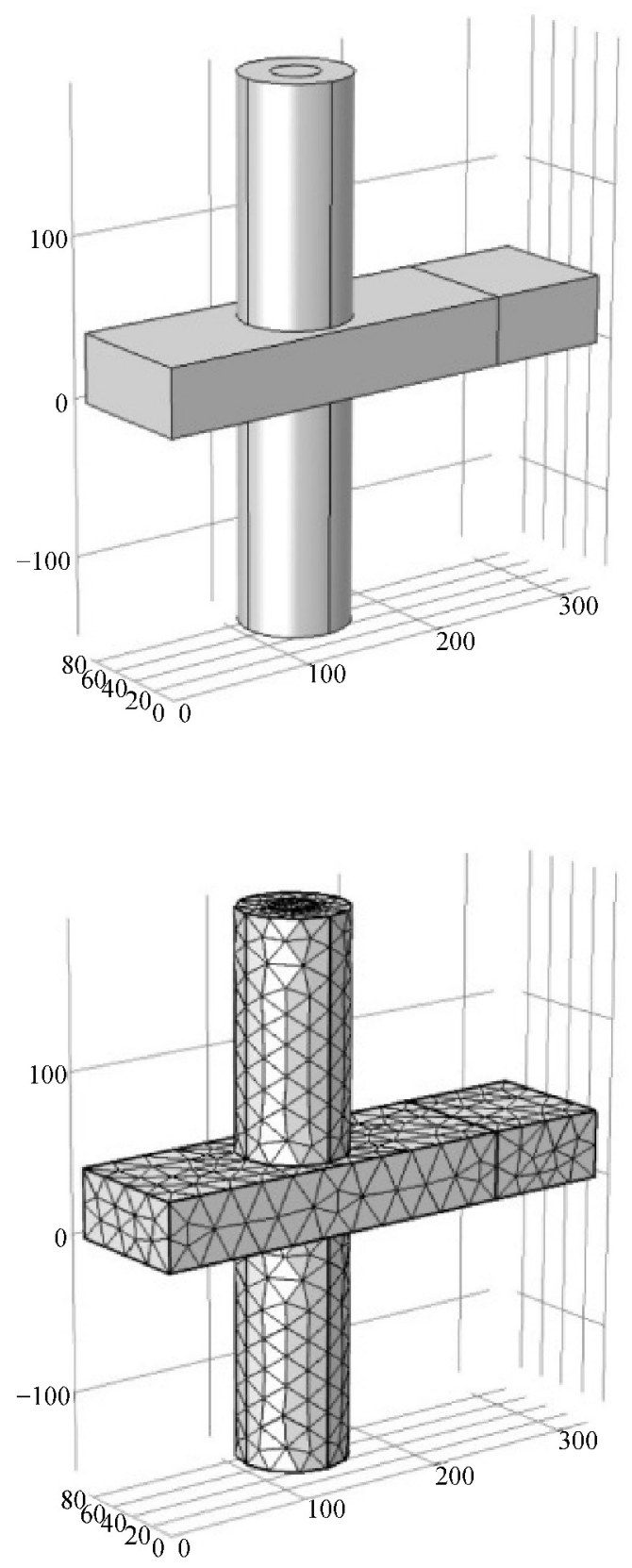

Fig. 4 The hydrodesulfurization microwave reaction system model. 
generalized gradient approximation (GGA) for calculation. Double numerical basis set plus polarization functions

Table 1 Calculation parameters

\begin{tabular}{lc}
\hline Theory & DFT \\
\hline Software & Materials Studio 6.1 \\
Module & $\mathrm{Dmol}^{3}$ \\
Functional & $\mathrm{GGA} / \mathrm{RPBE}$ \\
Basis set & $\mathrm{DNP}$ \\
Density mixing charge & 0.03 \\
SCF tolerance & $1.0 \times 10^{-6} \mathrm{Ha}$ \\
Convergence tolerance of energy & $1 \times 10^{-5} \mathrm{Ha}$ \\
Convergence tolerance of Max. force & $0.002 \mathrm{Hatree} / \AA$ \\
Convergence tolerance of Max. displacement & $0.005 \AA$ \\
\hline
\end{tabular}

(DNP) were employed. The calculation details are shown in Table 1.

\subsection{Reaction kinetics analysis}

The reaction of thiophene and hydrogen generates hydrocarbons and $\mathrm{H}_{2} \mathrm{~S}$. The main reaction is as follows:

$$
\mathrm{C}_{4} \mathrm{H}_{4} \mathrm{~S}+4 \mathrm{H}_{2} \rightarrow \mathrm{C}_{4} \mathrm{H}_{10}+\mathrm{H}_{2} \mathrm{~S}
$$

Based on the characteristics of HDS reaction, the following kinetic model can be proposed:

$$
-r=-\frac{\mathrm{d} C}{\mathrm{~d} t}=k C^{\alpha}{P_{\mathrm{H}_{2}}}^{\beta},
$$

where $r$ is the reaction rate, $\mathrm{mol} \cdot \mathrm{m}^{-3} \cdot \mathrm{s}^{-1} ; C$ is the concentration of sulfur materials in reactants, $\mathrm{mol} \cdot \mathrm{m}^{-3} ; P$ is hydrogen pressure, MPa; $\alpha, \beta$ are the reaction orders of the concentration of sulfur components and hydrogen pressure respectively; $k$ is the reaction rate constant, which is temperature dependent and obeys the Arrhenius equation:

$$
k=A \exp \left(-E_{\mathrm{A}} / \mathrm{R} T\right),
$$

where $A$ is the pre-exponential factor $\left(\mathrm{s}^{-1}\right) ; E_{\mathrm{A}}$ is the apparent activation energy, $\mathrm{J} \cdot \mathrm{mol}^{-1}$; $\mathrm{R}$ is the gas constant, $8.314 \mathrm{~J} \cdot \mathrm{mol}^{-1} \cdot \mathrm{K}^{-1}$; and $T$ is the reaction temperature, $\mathrm{K}$.

Excess hydrogen in the reaction process was used in the HDS experiments, therefore the hydrogen pressure is kept constant, and Eq. (8) can be rewritten as Eq. (10):

$$
-r=-\frac{\mathrm{d} C}{\mathrm{~d} t}=k C^{\alpha}
$$

Equation (11) can be achieved by integrating Eq. (10) when $\alpha=1$,

$$
k \tau=\ln \left(C_{\text {in }} / C_{\text {out }}\right),
$$

$C_{\text {in }}$ and $C_{\text {out }}$ indicate the concentrations of thiophene at the point of inlet and outlet, respectively. There is a linear relationship between $\ln C$ and reaction time according to Eq. (11) of the typical features of first order reaction. After calculating the reaction rate constant at different temperatures, Eq. (12) can be used to calculate the corresponding pre-exponential factor and activation energy.

$$
\ln k=\ln A-E_{\mathrm{A}} / \mathrm{R} T .
$$

\section{Results and discussion}

\subsection{Performance of microwave assisted HDS}

The influences of the operating conditions, such as microwave power, reaction temperature, pressure, hydrogen/oil ratio and WHSV on the HDS performance of thiophene were reported in our previous work [32]. A pressure of $2 \mathrm{MPa}$, WHSV of $2 \mathrm{~h}^{-1}$, hydrogen/oil ratio of 200:1 and a various microwave power levels at different temperatures were applied. The HDS efficiency by using microwave heating was compared to that from conventional heating at the same conditions.

The error for the data in Fig. 5 was proved to be $\pm 0.8 \%$. As shown in Fig. 5, the HDS ratios of the experiments with microwave heating was always higher than the ones achieved by conventional heating, this indicates the enhancement of the HDS of thiophene by microwave heating. The HDS ratio reached its highest value of $97 \%$ at $280^{\circ} \mathrm{C}$ with microwave heating, while it only achieved $92 \%$ with conventional heating. The biggest difference $(14 \%)$ between the experiments with microwave and conventional heating was observed at $240^{\circ} \mathrm{C}$. The reaction rate enhancement with the microwave can be attributed to thermal effect or non-thermal effect, to elucidate this, the reasons for HDS performance improvement were analyzed

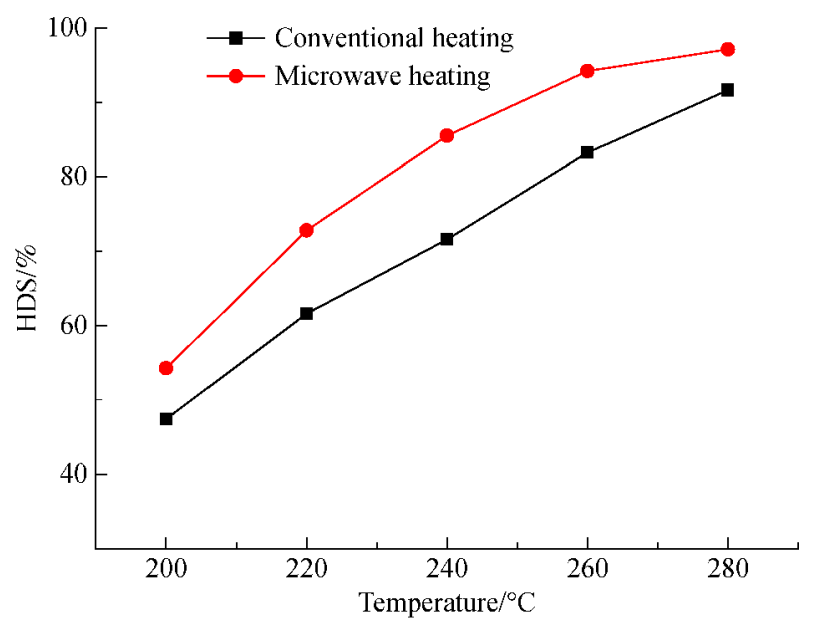

Fig. 5 Influence of microwave heating and conventional heating on the HDS performance of FCC gasoline model compound. 
in detail.

From component analysis, the olefins inside the gasoline model oil are saturated at all the operating conditions, thus the HDS selectivity was not revealed in this paper, however, from our present work, for the real FCC gasoline samples, the selectivity was highly improved under microwave enhancement.

\subsection{Microwave thermal effect}

According to the literature, reaction rate enhancement can be caused by microwave thermal effect, i.e., due to the hotspot formation during the heterogeneous catalysis. Due to the large difference between the dielectric loss of $\mathrm{MoS}_{2}$ and $\gamma-\mathrm{Al}_{2} \mathrm{O}_{3}$, the $\mathrm{MoS}_{2}$ particles may absorb more microwave energy than $\gamma-\mathrm{Al}_{2} \mathrm{O}_{3}$. This uneven heating would result in hot spots, leading to a significant difference in thiophene conversion. At higher temperatures, the difference in thiophene conversions obtained using both heating methods was reduced $[11,34,35]$. Based on the hot spot assumption, the temperature within the catalyst sites are higher, thus, for this exothermic reaction, the equilibrium will shift to a less favorable direction, making smaller temperature difference in thiophene conversion at higher temperatures [11]. Nevertheless, the slight difference in the HDS performance at lower temperatures was thought to be due to the lower microwave power level required to keep that reaction temperature, and thus the corresponding electric field strength is lower, making the thermal effect smaller.

The electromagnetic field was found to be non-uniform through the microwave electromagnetic field simulation, indicating of uneven heating (Fig. 6 and Fig. 7). However, hot spots were not observed, which was thought that the continuous HDS system eliminated the occurrence of hot spots. Even for that, the average temperature from calculation was found higher than that measured from experiments.

The reaction kinetics were then investigated, and the reaction rate constants under different heating methods are shown in Table 2. Clearly, the reaction rate can be significantly improved under microwave heating. In order to determine if the improvement is caused by temperature enhancement, the average temperature under microwave heating was found to be $10^{\circ} \mathrm{C}-15^{\circ} \mathrm{C}$ higher than that from conventional heating at temperatures below $240^{\circ} \mathrm{C}$ and $16^{\circ} \mathrm{C}-22^{\circ} \mathrm{C}$ higher at above $240^{\circ} \mathrm{C}$. Figure 8 was achieved based on the data from Table 2, the polynomial fittings were obtained for the relationship of reaction rate constant from conventional heating and microwave heating:

$$
\begin{aligned}
& k_{\mathrm{con}}=0.67637-0.00696 T+1.9717 \times 10^{-5} T^{2}, \\
& k_{\mathrm{mw}}=0.02733-0.00233 T+1.30649 \times 10^{-5} T^{2} .
\end{aligned}
$$

The equations for reaction rate constants are not identical for conventional heating and microwave heating. Furthermore, the "actual" $k$ for microwave enhanced HDS was obtained based on Eq. (13). According to Table 2, the adjusted data of $k$ is still smaller than that achieved from microwave heating, providing the evidence for the existence of non-thermal effect.

\subsection{Microwave non-thermal effect}

3.3.1 Analysis of apparent active energy and pre-exponential factor $A$

The pre-exponential factor $A$ and the reaction activation energy $E_{\mathrm{A}}$ can be determined according to the slope and intercept of the line gained from Fig. 9 and Eq. (12). The results are shown in Table 3. It can be seen from Table 3 that instead of being reduced, the apparent activation energy was higher for the microwave assisted HDS. At the same time, the pre-exponential factor, $A$, from the microwave assisted HDS was significantly increased. It is therefore the pre-exponential factor contributed to the increase in the reaction rate constant. The pre-exponential factor, also referred to as the frequency factor, depends on how often molecules collide when all concentrations are $1 \mathrm{~mol} \cdot \mathrm{L}^{-1}$ and whether the molecules are properly oriented when they collide. Dipole molecules are sensitive to external electric fields, they will attempt to align with the external electric fields by rotation. This realignment is hindered by the presence of other molecules, and random collisions will therefore be induced, which enhances the value of the pre-exponential factor.

The results from this work contradicts the normal considerations that microwave can reduce the activated energy of the reactions [10]. Thus, an analysis of the mechanism of microwave assisted thiophene HDS is necessary, to achieve a deeper understanding of microwave assisted HDS.

\subsubsection{Theoretical study of microwave enhanced HDS}

Sulfur-, nitrogen- and oxygen-containing compounds within FCC gasoline are polar in nature and often have relatively high dielectric constants and dipole moments. Furthermore, the dielectric properties of the active components of HDS catalysts are high, while those of the support are low $[34,36,37]$. Therefore, microwave energy can heat these organic compounds preferentially and further induce desulfurization assisted by the HDS catalysts.

\subsubsection{Sulfur distribution changes via HDS}

Sulfur distribution of the thiophene model oils before and after the HDS process was investigated by gas chromatographic analysis. The results are shown in Table 4 . 


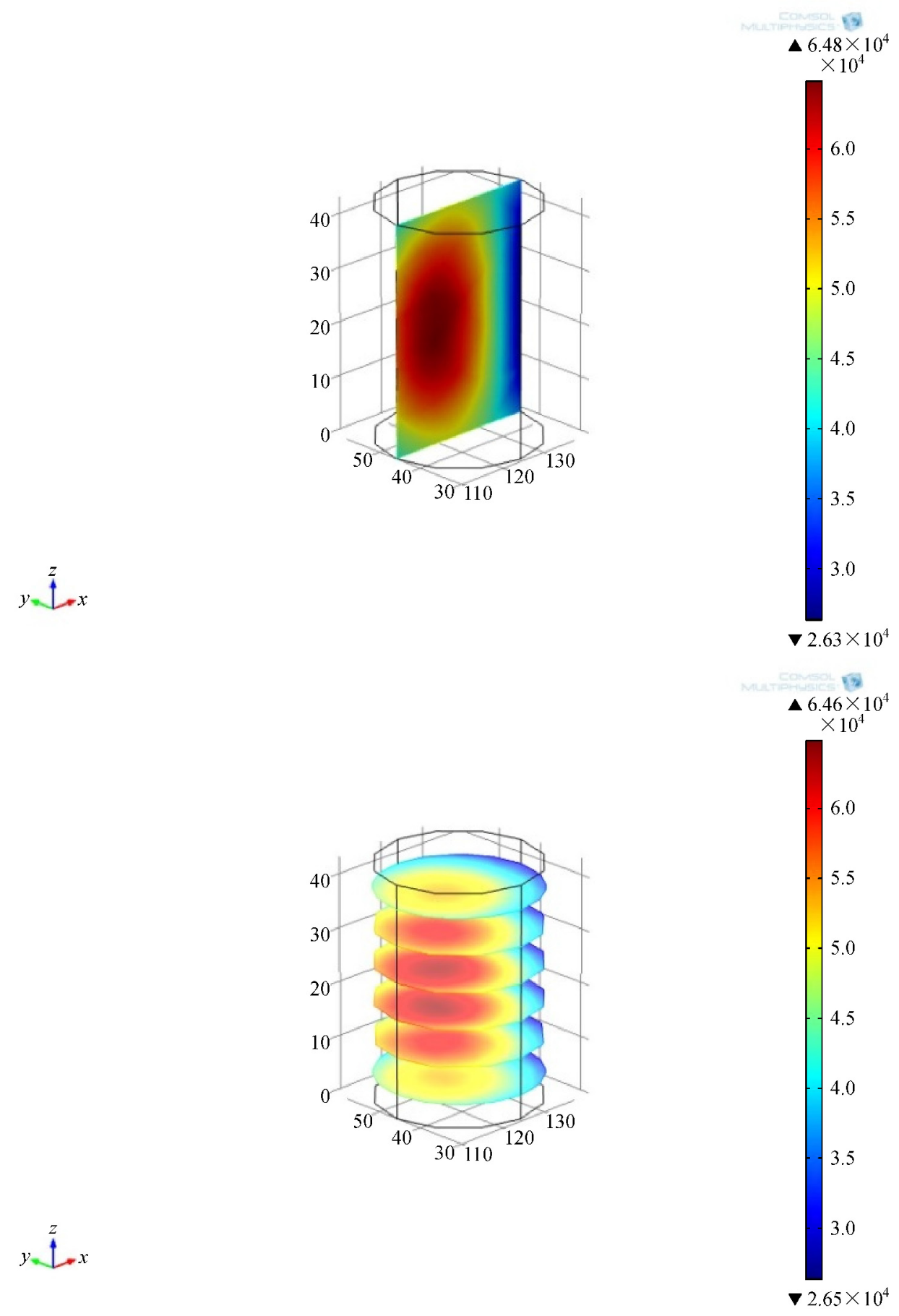

Fig. 6 Electric field distribution at the temperature of $240^{\circ} \mathrm{C}$.

Researchers commonly believe that thiophene HDS occurs via two parallel pathways: the DDS route to form intermediate products of butadiene and butenes and the HYD route to form intermediates of dihydrothiophene and tetrahydrothiophene. The intermediate 1-butanethiol is formed via both routes (Figs. 1 and 2) [19-22]. However, there has been considerable debate regarding the mechanism of thiophene HDS. It has been difficult to establish to what extent prehydrogenation to dihydrothiophene or tetrahydrothiophene may be necessary before $\mathrm{S}-\mathrm{C}$ bond scission $[20,38,39]$. From Table 4, the contents of thiophene and total sulfur via microwave HDS were lower than those from conventional HDS at the same temperature, indicating that microwave can highly enhance the HDS reaction. At the same conditions, the HDS activities of sulfur compounds decrease in the order of mercaptan, tetrahydrothiophene and thiophene. However, from thermodynamic analysis, at low temperature (such as 


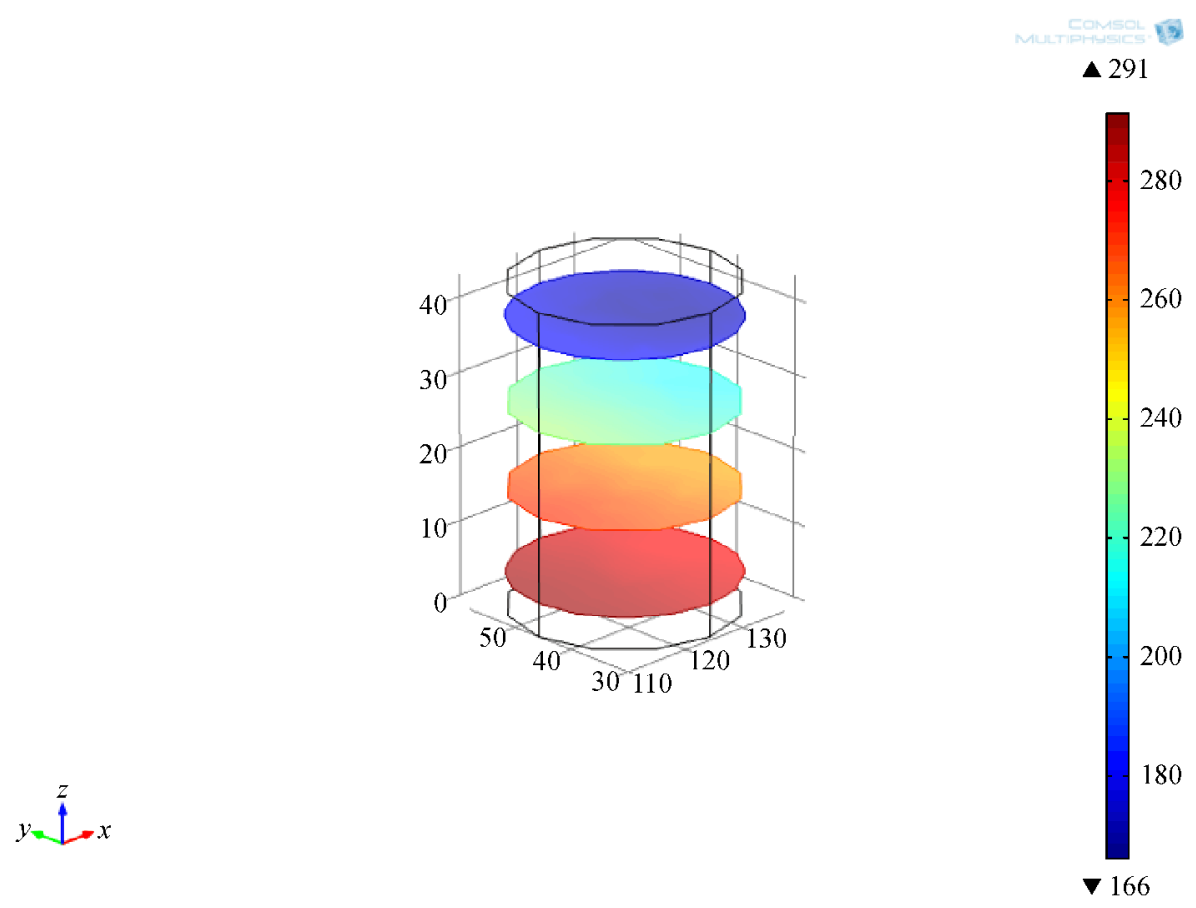

Fig. 7 Temperature distribution within the catalyst.

Table 2 HDS reaction rate constants at different temperatures

\begin{tabular}{lccc}
\hline Temperature $/{ }^{\circ} \mathrm{C}$ & $k$ (conventional heating) $/ \mathrm{s}^{-1}$ & $k$ (microwave heating) $/ \mathrm{s}^{-1}$ & $k$ (adjusted for microwave $) / \mathrm{s}^{-1}$ \\
\hline 200 & 0.07 & 0.09 & 0.09 \\
220 & 0.11 & 0.14 & 0.12 \\
240 & 0.14 & 0.21 & 0.19 \\
260 & 0.20 & 0.32 & 0.27 \\
280 & 0.28 & 0.40 & 0.37 \\
\hline
\end{tabular}

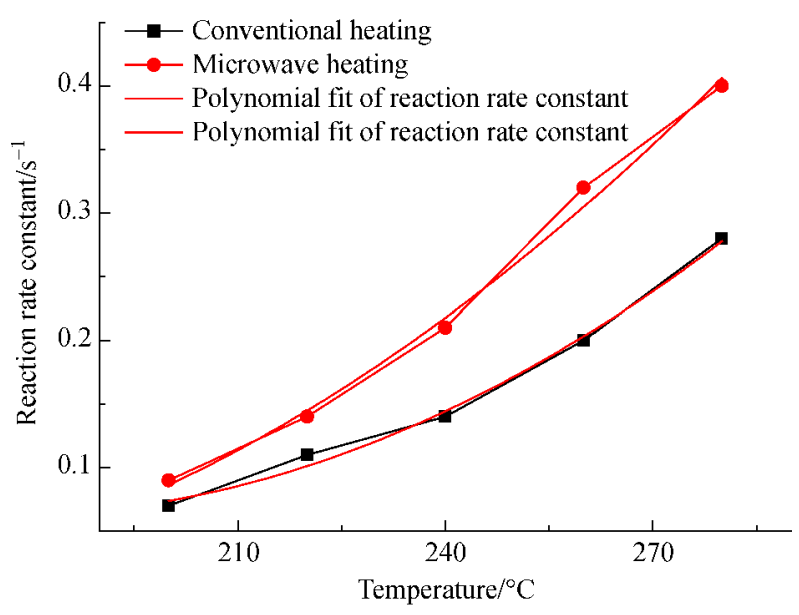

Fig. 8 The relationship between the reaction rate constant and temperature under conventional heating and microwave heating. $220^{\circ} \mathrm{C}$ ), the equilibrium constant of thiophene is much higher than those of 1-butanethiol and tetrahydrothiophene [40]. This could explain the tetrahydrothiophene and 1-butanethiol detected in the products, even at high temperature of $280^{\circ} \mathrm{C}$.

Under the HDS conditions, $\mathrm{H}_{2}$ strips sulfur from the catalyst, makes it partly reduced, and starts to crack hydrocarbons by hydrogenolysis. $\mathrm{CH}_{4}$ will be formed, reacting with $\mathrm{H}_{2} \mathrm{~S}$ to $\mathrm{CS}_{2}$. The formation of $\mathrm{CS}_{2}$, thus, has nothing to do with the DDS or HYD mechanisms. As shown in Table 4, the contents of tetrahydrothiophene were relatively higher through microwave treatment than those from conventional heating, whilst the contents of 1-butanethiol were lower under microwave irradiation. As from Figs. 1 and 2, both reaction routes can form 1-butanethiol, whereas tetrahydrothiophene can only be formed through HYD pathway, therefore one can conclude that the HDS process tends to proceed via HYD route 


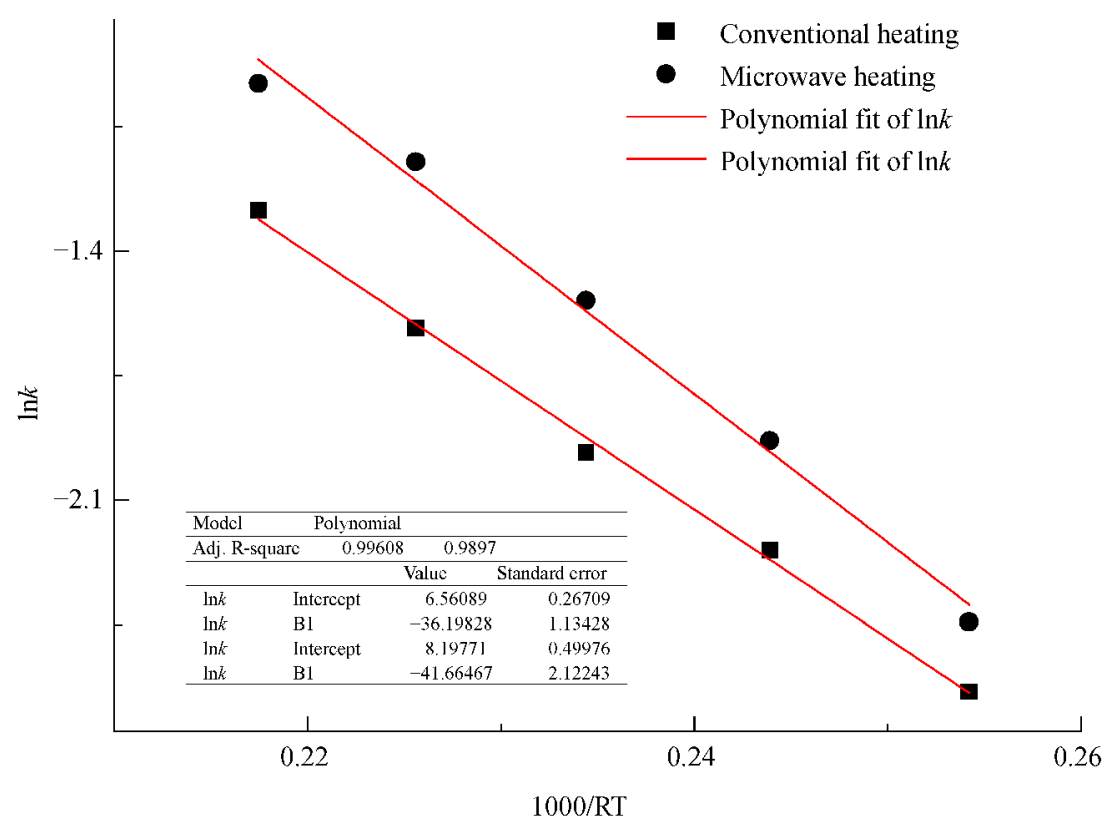

Fig. 9 Linear regression of $\ln k$ versus 1000/RT under conventional and microwave HDS.

Table 3 Pre-exponential factors and activation energy achieved

\begin{tabular}{|c|c|c|c|c|c|c|}
\hline \multirow{2}{*}{$\begin{array}{l}\text { Factors } \\
E_{\mathrm{A}} /\left(\mathrm{kJ} \cdot \mathrm{mol}^{-1}\right)\end{array}$} & & \multicolumn{2}{|c|}{ Conventional heating } & \multicolumn{3}{|c|}{ Microwave heating } \\
\hline & & \multirow{2}{*}{\multicolumn{2}{|c|}{36.2}} & \multicolumn{3}{|c|}{41.7} \\
\hline \multicolumn{2}{|l|}{$A / \mathrm{s}^{-1}$} & & & & 363 & \\
\hline $\begin{array}{l}\text { Temperature } \\
{ }^{\circ} \mathrm{C}\end{array}$ & $\begin{array}{l}\mathrm{CS}_{2} \\
/ \mathrm{ppm}\end{array}$ & $\begin{array}{l}\text { Thiophene } \\
\text { /ppm }\end{array}$ & $\begin{array}{l}\text { 1-Butanethiol } \\
/ \mathrm{ppm}\end{array}$ & $\begin{array}{l}\text { Tetrahydrothiophene } \\
\text { /ppm }\end{array}$ & $\begin{array}{l}\text { Total sulfur } \\
\text { /ppm }\end{array}$ & $\begin{array}{c}\text { Thiophene removal } \\
1 \%\end{array}$ \\
\hline Raw material & 3.65 & 277.49 & 0 & 0 & 281.14 & \\
\hline $200 \mathrm{MW}$ & 7.66 & 116.78 & 0.68 & 3.58 & 128.7 & 57.92 \\
\hline $220 \mathrm{MW}$ & 16.04 & 58.52 & 0.43 & 1.59 & 76.58 & 78.91 \\
\hline $240 \mathrm{MW}$ & 11.21 & 28.7 & 0.28 & 0.63 & 40.82 & 89.66 \\
\hline $260 \mathrm{MW}$ & 4.95 & 10.79 & 0.10 & 0.46 & 16.3 & 96.11 \\
\hline $280 \mathrm{MW}$ & 1.54 & 5.42 & 0.22 & 0.90 & 8.08 & 98.05 \\
\hline 200 & 5.67 & 140.29 & 0.73 & 1.28 & 147.97 & 49.44 \\
\hline 220 & 17.49 & 88.91 & 0.48 & 1.19 & 108.07 & 67.96 \\
\hline 240 & 14.11 & 63.4 & 0.59 & 1.87 & 79.97 & 77.15 \\
\hline 260 & 5.27 & 42.04 & 0.29 & 0.61 & 48.21 & 84.85 \\
\hline 280 & 4.22 & 18.57 & 0.15 & 0.57 & 23.51 & 93.31 \\
\hline
\end{tabular}

a) MW: via microwave treatment. Error: $\pm 1 \%$.

under microwave conditions. Compared to the hydrocarbon content, the thiophene content was quite low, and the produced butadiene and butene are easily saturated, thus these compounds were not detected.

\subsubsection{The theory of microwave enhanced HDS}

The microwave heating effect arises from the interaction between the electric field and the charged molecules in the material. The power absorbed by a material is dependent on the dielectric properties of the material. The absorbed power density $\left(P_{\mathrm{d}}\right)\left(\mathrm{W} \cdot \mathrm{m}^{-3}\right)$, is given by $[41]$ :

$$
P_{\mathrm{d}}=2 \pi f \varepsilon_{0} \varepsilon^{\prime \prime}|E|^{2},
$$

where $f$ is microwave frequency $(\mathrm{Hz}) ; \varepsilon_{0}$ is the dielectric permittivity of free space, $8.85 \times 10^{-12} \mathrm{~F} \cdot \mathrm{m}^{-1} ; E$ is the electric field strength inside the material $\left(\mathrm{V} \cdot \mathrm{m}^{-1}\right) ; \varepsilon^{\prime \prime}$ is the dielectric loss factor. Equation (15) states that the power 
Table 5 Dipole moment values achieved from $\mathrm{MS} \mathrm{Dmol}^{3}$ modular

\begin{tabular}{ccccccc}
\hline Material & Thiophene & Tetrahydrothiophene & 2,3-Dihydrothiophene & 1-Butanethiol & Butadiene $^{\text {CS }_{2}}$ \\
\hline$\mu$ /debye & 0.3679 & 1.9588 & 1.4573 & 1.6724 & 0.0022 & 0.0006 \\
\hline
\end{tabular}

absorbed varies linearly with the loss factor, i.e., a high loss material will be heated more rapidly than a low loss material. In general, the higher the induced polarity, the greater the influence that microwaves may induce. The polarities of all components present in the reaction medium play an important role in the microwave heating rate. Thus, the dipole moment was investigated through Materials Studio, and the results are listed in Table 5. The higher the dipole moment, the higher the dielectric properties of the material are. Therefore, the polar sulfur compounds within the FCC gasoline model oil would readily interact with the microwave electromagnetic field and absorb more microwave energy (Eq. (15)). Carbon disulfide, a non-polar material formed during HDS reaction, is difficult to treat by microwave, hindering its continuous reaction. Thus, there

Table 6 Pre-exponential factors and activation energy achieved

\begin{tabular}{lcc}
\hline Factors & Conventional heating & Microwave heating \\
\hline$E_{\mathrm{A}} /\left(\mathrm{kJ} \cdot \mathrm{mol}^{-1}\right)$ & 29.1 & 33.0 \\
$A / \mathrm{s}^{-1}$ & 166 & 465 \\
\hline
\end{tabular}

would be a higher content of $\mathrm{CS}_{2}$ in the reaction system under microwave irradiation than with conventional heating.

The bond order is a physical parameter describing the bond strength between adjacent atoms in a molecule. The higher the bond order, the stronger the bond will be. As shown in Fig. 10, the bond order of the $\mathrm{C}-\mathrm{S}$ bond was reduced from 1.289 in thiophene to 1.044 in tetrahydrothiophene. It indicates that the $\mathrm{C}-\mathrm{S}$ bond is weakened after hydrogenation and is more prone to dissociation. The intermediate products of 2,3-dihydrothiophene and tetrehydrothiophene from the HYD pathway have certain polarity (Table 6 and Fig. 10) and are easily heated by microwave. Therefore, once 2,3dihydrothiophene, tetrehydrothiophene are generated, they will continue to react immediately under microwave irradiation to produce the final product. This theory agrees with that of Rodríguez et al. [10], who stated that if the relative polarity increases from the reactant to the transition structure, the acceleration due to an increase in microwave absorbance of the intermediate could occur. This effect is
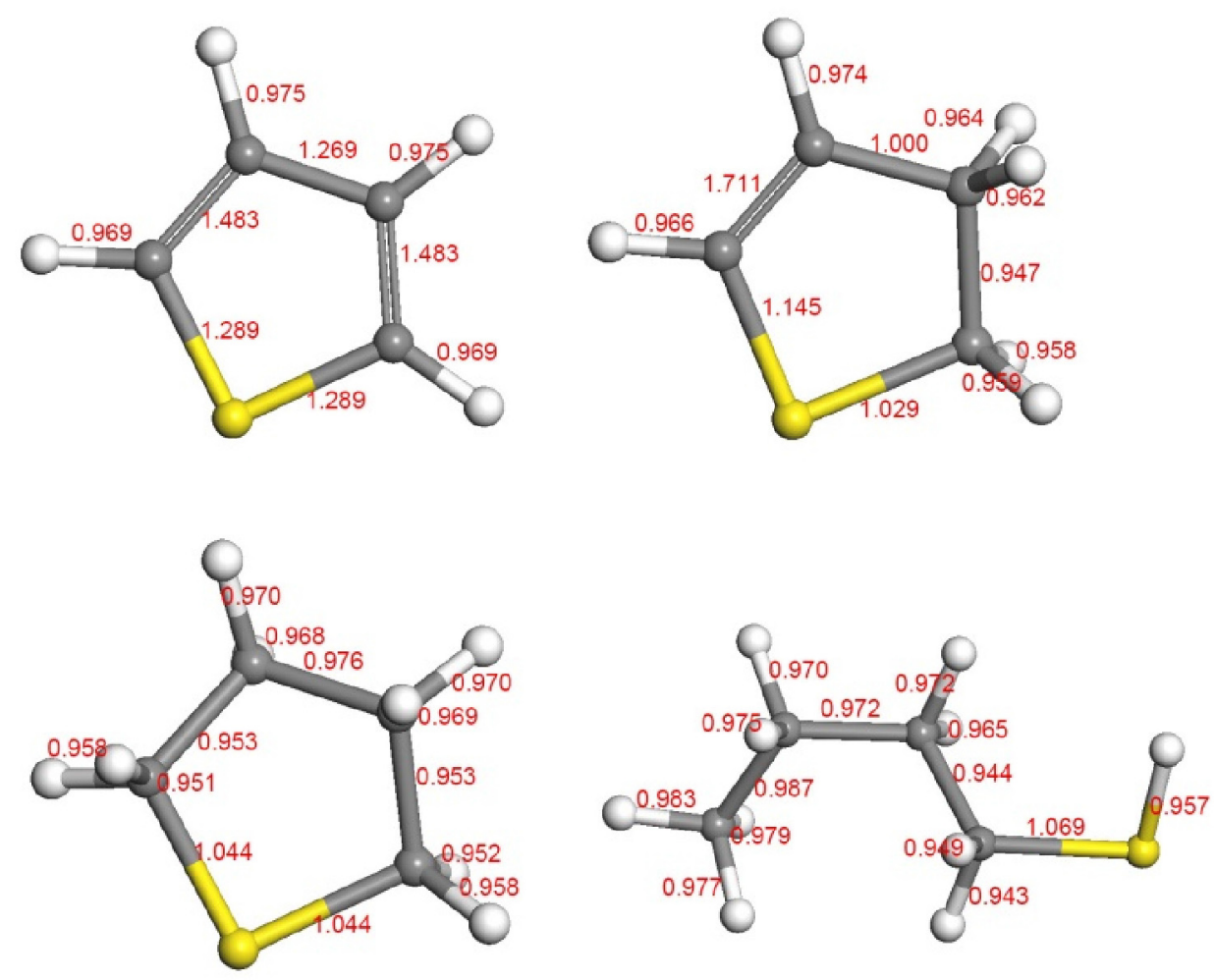

Fig. 10 Mayer bond order of sulfur materials. 
particularly important in produce-like transition states according to Hammond's postulate $[10,42]$.

\subsubsection{Pathways of HDS process under microwave irradiation}

The mechanism of HDS is highly dependent on the interaction between sulfides and catalysts. Thiophene adsorption is the first step in the HDS catalytic process [23]. Studies have shown that thiophene is weakly chemisorbed to the catalyst surface in $\eta^{5}$ geometry (parallel to the surface) and $\eta^{1}$ (S) geometry (upright Sbind) $[19,24,43-45]$. Wiegand et al. [24] reported that the orientation of thiophene with respect to metal surfaces is sensitive to its coverage and the coverage of co-adsorbed hydrocarbons and sulfur. On most surfaces, a parallel geometry is favored at low coverage and perpendicular inclination of thiophene ring is favored at high coverage. These coverage-dependent phenomena are probably due to the intermolecular interactions of sulfur components with catalysts, and also related to the steric interactions with neighboring ligands in a discrete cluster or complex. Borges et al. [18] found that thiophene coordinates with two $\mathrm{Mo}_{\text {IV }}$ atoms through a distorted bridge- $\eta^{5}$ bonding, even if the optimization process started from a $\eta^{1}$ geometry, and the results is consistent with other researchers $[25,26]$. After adsorption the lengths of $\mathrm{C}-\mathrm{S}$ bond, the $\mathrm{C}=\mathrm{C}$ double bonds increased by 0.1 and $0.05 \AA$ respectively. From the electronic analysis, a donation of thiophene $\pi$ electrons to the catalyst surface through Mo1 and a back charge donation through Mo2 of the catalyst to $\mathrm{S}$ of the absorbed thiophene molecule were also observed $[18,23,26]$. The bridge- $\eta^{5}$ type thiophene configuration indicates that the aromatic character of the thiophene ring was destroyed by the adsorption. This means that an adsorption geometry is the key factor to weaken the $\mathrm{C}-\mathrm{S}$ bond and to reduce the aromatic character of the thiophene ring, i.e., making the molecule more prone to both desulfurization and hydrogenation [25].

It was suggested that the cleavage of the $\mathrm{C}-\mathrm{S}$ bond occurs when thiophene is adsorbed on a coordinately unsaturated Mo site via the sulfur atom in the $\sigma$ mode [19], i.e., the DDS pathway is more likely to occur through $\sigma$ adsorption of thiophene molecule via sulfur atom $\left(\eta^{1}(S)\right)$, and the HYD pathway proceeds through $\pi$ adsorption $\left(\eta^{5}\right)$ of the reactant via the aromatic system. The interaction of thiophene with molybdenum clusters from the calculations modeling show that the lengths of $\mathrm{C}=\mathrm{C}$ and $\mathrm{C}-\mathrm{S}$ bonds increased after adsorption through $\eta^{5}[18,46]$, making thiophene molecules more polar, thus would absorb more microwave energy, i.e., microwave would further enhance the HDS process. Therefore, under microwave irradiation, HDS favors the hydrogenation route. However, the S-M (sulfur-metal) bond formed from $\sigma$ adsorption $\left(\eta^{1}(S)\right)$ would make the structure more polar, hindering the adsorption and decreasing the stability of the S-M structure
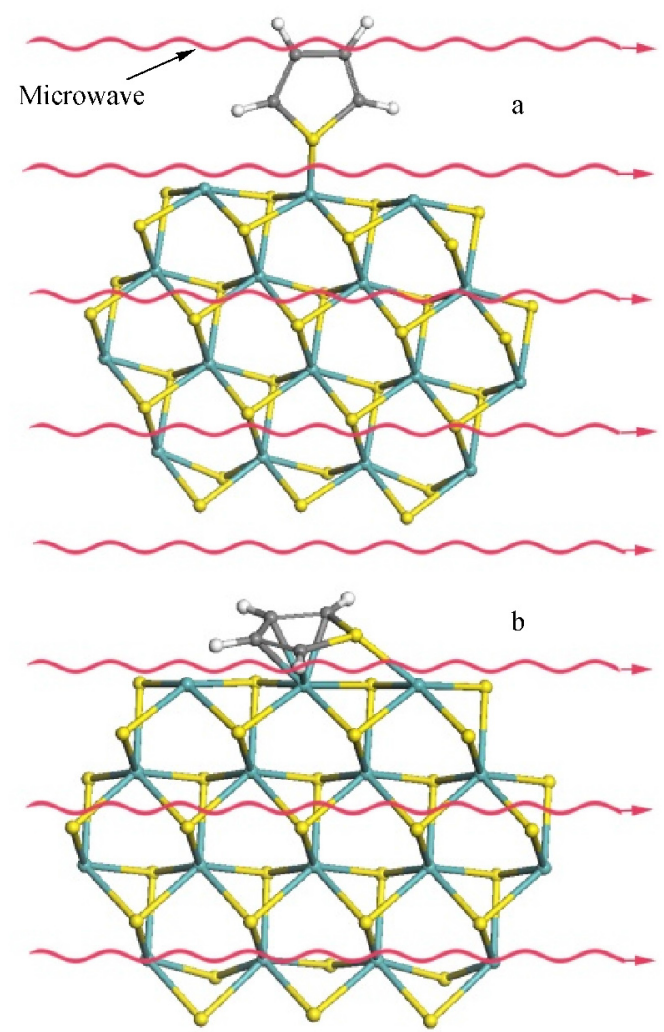

Fig. 11 Adsorption of thiophene through (a) $\eta^{1}$ and (b) $\eta^{5}$ modes on an $\mathrm{MoS}_{2}$ cluster model catalyst.

in a strong electromagnetic field (Fig. 11). For $\pi\left(\eta^{5}\right)$ adsorption, since the thiophene molecular absorbed is parallel to the catalyst surface, which in theory is little influenced by microwave field. Based on the above discussions, after $\eta^{5}$ adsorption, the structure of thiophene becomes more polar, therefore microwave will highly enhance the reaction through this route.

The sulfur coverage was high at the beginning of the HDS process. In this case the adsorption was mainly through $\eta^{1}(\mathrm{~S})$, which would be hindered by microwave electromagnetic field as discussed above. This could explain the higher apparent activation energy for microwave heating compared to conventional heating. To verify this conclusion, a series of HDS experiments were carried out using a lower thiophene content model oil as the raw material under microwave and conventional heating methods. These experiments were designed to investigate whether the adsorption mode would change at different initial sulfur coverage. The thiophene content was 203.58 $\mathrm{ppm}$ for the experiments. Microwave assisted HDS reactions were employed at a pressure of $2 \mathrm{MPa}$, WHSV of $2 \mathrm{~h}^{-1}$, hydrogen/oil ratio of 200:1, and temperatures of $240^{\circ} \mathrm{C}, 250^{\circ} \mathrm{C}, 260^{\circ} \mathrm{C}$ and $270^{\circ} \mathrm{C}$. The same temperatures were used for the HDS reactions with conventional heating. The desulfurization results and the constant reaction rates calculated based on Eq. (11) at various 
Table 7 HDS ratio and reaction rate constants at different temperatures

\begin{tabular}{lcccc}
\hline Temperature $/{ }^{\circ} \mathrm{C}$ & HDS ratio (conventional heating) $/ \%$ & HDS ratio (microwave heating) $/ \%$ & $k$ (conventional heating) $/ \mathrm{s}^{-1}$ & $k\left(\mathrm{microwave}\right.$ heating) $/ \mathrm{s}^{-1}$ \\
\hline 240 & 81.06 & 84.73 & 0.18 & 0.21 \\
250 & 84.50 & 87.66 & 0.21 & 0.23 \\
260 & 87.77 & 91.64 & 0.23 & 0.28 \\
270 & 90.46 & 94.12 & 0.26 & 0.32 \\
280 & 93.58 & 96.11 & 0.30 & 0.36 \\
\hline
\end{tabular}

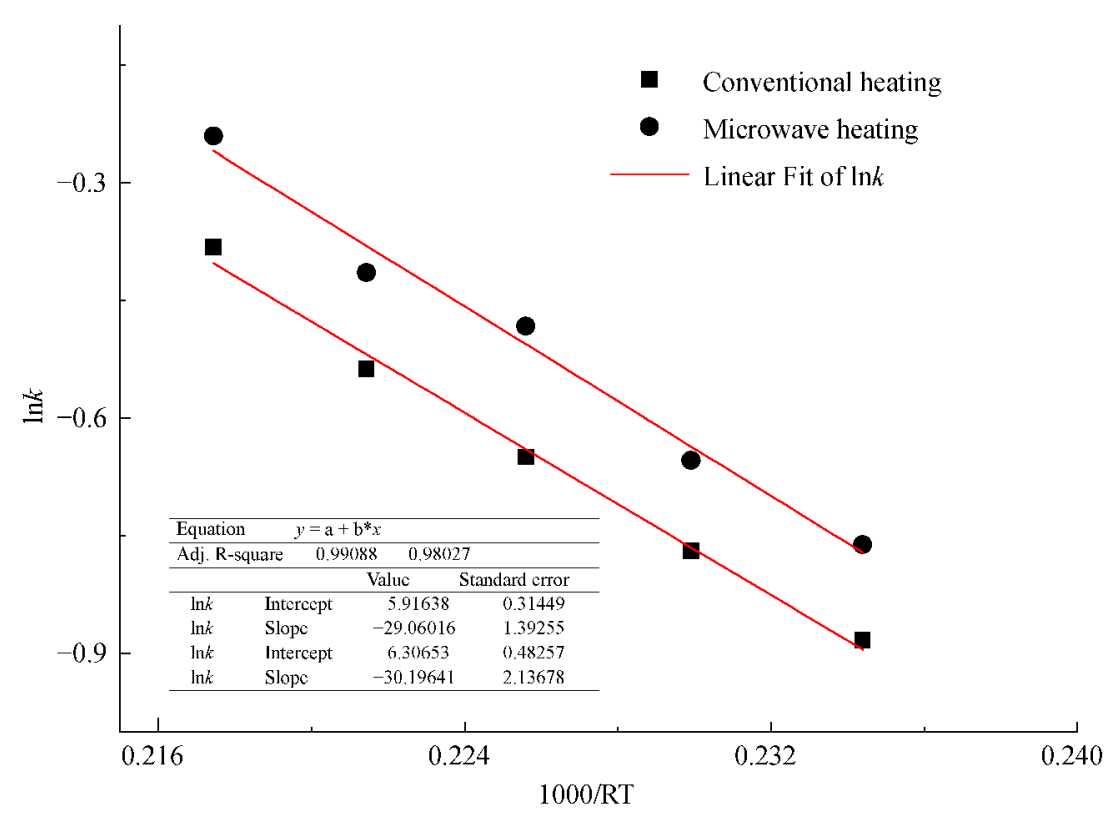

Fig. 12 Linear regression of $\ln k$ versus 1000/RT under conventional and microwave HDS.

temperatures are shown in Table 7. The apparent activation energy and pre-exponential factor can be achieved based on Fig. 12 and Eq. (12).

Compared with the results from Table 2, when the contents of thiophene decreased from 277.49 to 203.58 ppm, the apparent activation energy decreased. The difference in the activation energy between conventional heating and microwave assisted HDS was also significantly reduced. These results highly support the above theory that the upright S-bind geometry under microwave is less stable in the microwave electromagnetic field. However, the parallel adsorption will be strengthened, and microwave electromagnetic field would enhance $\eta^{5}$ adsorption and the HDS process would mainly follow the hydrogenation route.

\section{Conclusions}

Microwave induced HDS of FCC gasoline proved to be an effective technology with less severe operating conditions than conventional heating. The difference was investigated through microwave thermal and non-thermal heating effects. It was found that microwave selective heating caused hot spots inside the catalyst, and then improved the reaction rate. From the analysis of the non-thermal effect, the molecular collisions were significantly enhanced under microwave irradiation. However, higher apparent activation energy was observed if microwave energy was applied during the HDS process. The difference in activation energy between the two heating methods was significantly reduced by decreasing the content of thiophene within the simulated model oil. This was due to the high thiophene content at the beginning, where $\eta^{1}$ adsorption is favored, whereas microwave will hinder this type of adsorption. As the reaction proceeded, the sulfur content decreased, the adsorption of thiophene changed to parallel adsorption $\left(\eta^{5}\right)$, which could be further enhanced by the microwave electromagnetic field. Therefore, one can conclude that under microwave irradiation, HDS tends to proceed along the hydrogenation route.

Acknowledgements This work was supported by the National Natural Science Foundation of China (Grant No. 21476258). 
Open Access This article is licensed under a Creative Commons Attribution 4.0 International License, which permits use, sharing, adaptation, distribution and reproduction in any medium or format, as long as you give appropriate credit to the original author(s) and the source, provide a link to the Creative Commons licence, and indicate if changes were made. The images or other third party material in this article are included in the article's Creative Commons licence, unless indicated otherwise in a credit line to the material. If material is not included in the article's Creative Commons licence and your intended use is not permitted by statutory regulation or exceeds the permitted use, you will need to obtain permission directly from the copyright holder. To view a copy of this licence, visit http://creativecommons.org/licenses/by/4.0/.

\section{References}

1. Kaufmann T G, Kaldor A, Stuntz G F, Kerby M C, Ansell L L. Catalysis science and technology for cleaner transportation fuels. Catalysis Today, 2000, 62(1): 77-90

2. Song C. An overview of new approaches to deep desulfurization for ultra-clean gasoline, diesel fuel and jet fuel. Catalysis Today, 2003, 86(1-4): 211-263

3. Liu N, Wang X, Xu W, Hu H, Liang J, Qiu J. Microwave-assisted synthesis of $\mathrm{MoS}_{2} /$ graphene nanocomposites for efficient hydrodesulfurization. Fuel, 2014, 119: 163-169

4. Shang H, Du W, Liu Z, Zhang H. Development of microwave induced hydrodesulfurization of petroleum streams: A review. Journal of Industrial and Engineering Chemistry, 2013, 19(4): 1061-1068

5. Ghosh P, Andrews A T, Quann R J, Halbert T R. Detailed kinetic model for the hydro-desulfurization of FCC naphtha. Energy \& Fuels, 2009, 23(12): 5743-5759

6. Wang H, Wu Y, Liu Z, He L, Yao Z, Zhao W. Deposition of $\mathrm{WO}_{3}$ on $\mathrm{Al}_{2} \mathrm{O}_{3}$ via a microwave hydrothermal method to prepare highly dispersed $\mathrm{W} / \mathrm{Al}_{2} \mathrm{O}_{3}$ hydrodesulfurization catalyst. Fuel, 2014, 136 : 185-193

7. Miadonye A, Snow S, Irwin D J G, Khan M R, Britten A J. Desulfurization of heavy crude oil by microwave irradiation. International Journal of Multiphase Flow, 2009, 63: 455-465

8. Mutyala S, Fairbridge C, Paré J R J, Bélanger J M R, Ng S, Hawkins R. Microwave applications to oil sands and petroleum: A review. Fuel Processing Technology, 2010, 91(2): 127-135

9. Leadbeater N E, Khan M R. Microwave-promoted desulfurization of heavy and sulfur-containing crude oil. Energy \& Fuels, 2008, 22(3): 1836-1839

10. Rodríguez A M, Prieto P, de la Hoz A, Díaz-Ortiz Á, Martín D R, García J I. Influence of polarity and activation energy in microwaveassisted organic synthesis (MAOS). ChemistryOpen, 2015, 4(3): 308-317

11. Zhang X, Hayward D O, Mingos D M P. Effects of microwave dielectric heating on heterogeneous catalysis. Catalysis Letters, 2003, 88(1/2): 33-38

12. Perry W L, Katz J D, Rees D, Paffet M T, Datye A K. Kinetics of the microwave-heated $\mathrm{CO}$ oxidation reaction over alumina-supported Pd and Pt catalysts. Journal of Catalysis, 1997, 171(2): 431-438

13. Booske J H, Cooper R F, Freeman S A. Microwave enhanced reaction kinetics in ceramics. Materials Research Innovations, 1997, 1(2): 77-84

14. Kappe $\mathrm{C}$ O. Microwave dielectric heating in synthetic organic chemistry. Chemical Society Reviews, 2008, 37(6): 1127-1139

15. Gao X, Li X G, Zhang J S, Sun J Y, Li H. Influence of a microwave irradiation field on vapor-liquid equilibrium. Chemical Engineering Science, 2013, 90: 213-220

16. Meredith R. Engineers Handbook of Industrial Microwave Heating. London: Institute of Electrical Engineers, 1998, 19-20

17. Raner K D, Strauss C R, Vyskoc F, Mokbel L. A comparison of reaction kinetics observed under microwave irradiation and conventional heating. Journal of Organic Chemistry, 1993, 58(4): 950-953

18. Borges I Jr, Silva A M, Aguiar A P, Borges L E P, Santos J C A, Dias M H C. Density functional theory molecular simulation of thiophene adsorption on $\mathrm{MoS}_{2}$ including microwave effects. Journal of Molecular Structure THEOCHEM, 2007, 822(1-3): 80-88

19. Mills P, Korlann S, Bussell M E, Reynolds M A, Ovchinnikov M V, Angelici R J, Stinner C, Weber T, Prins R. Vibrational study of organometallic complexes with thiophene ligands: Models for adsorbed thiophene on hydrodesulfurization catalysts. Journal of Physical Chemistry A, 2001, 105(18): 4418-4429

20. Moses P, Hinnemann B, Topsoe H, Norskov J. The hydrogenation and direct desulfurization reaction pathway in thiophene hydrodesulfurization over $\mathrm{MoS}_{2}$ catalysts at realistic conditions: A density functional study. Journal of Catalysis, 2007, 248(2): 188-203

21. Wang H, Iglesia E. Thiophene hydrodesulfurization catalysis on supported $\mathrm{Ru}$ clusters: Mechanism and site requirements for hydrogenation and desulfurization pathways. Journal of Catalysis, 2010, 273(2): 245-256

22. Zheng P, Duan A, Chi K, Zhao L, Zhang C, Xu C, Zhao Z, Song W, Wang $X$, Fan J. Influence of sulfur vacancy on thiophene hydrodesulfurization mechanism at different $\mathrm{MoS}_{2}$ edges: A DFT study. Chemical Engineering Science, 2017, 164: 292-306

23. Ma X, Schobert H H. Molecular simulation on hydrodesulfurization of thiophenic compounds over $\mathrm{MoS}_{2}$ using ZINDO. Journal of Molecular Catalysis A Chemical, 2000, 160(2): 409-427

24. Wiegand B C, Friend C M. Model studies of the desulfurization reactions on metal surfaces and in organometallic complexes. ChemInform, 1992, 23: 491-504

25. Cristol S, Paul J F, Schovsbo C, Veilly E, Payen E. DFT study of thiophene adsorption on molybdenum sulfide. Journal of Catalysis, 2006, 239(1): 145-153

26. Raybaud P, Hafner J, Kresse G, Toulhoat H. Adsorption of thiophene on the catalytically active surface of $\mathrm{MoS}_{2}$ : An ab initio, local-density-functional study. Physical Review Letters, 1998, 80(7): 1481-1484

27. Shang H, Zhao J M, liu Z C, Bai B, Zhang H C. China Patent, 201210160627.4, 2015-04-01

28. Shang H, Zhao J M. China Patent, 201210160686.1, 2015-01-07

29. Shang H, Zhao J M, liu Z C, Zhang H C. China Patent, 201210320334.8, 2014-09-03

30. Shang H, Zhao J M, Liu Z C. China Patent, 201210454604.4, 201506-03

31. Shang H, Zhao J M, Zhang W H. China Patent, 201410156106.0, 2017-05-03

32. Shang H, Zhang H, Li W, Liu Z, Bai B, Liu Z. Study on the hydrodesulfurization of thiophene model compound under microwave irradiation. Journal of Kunming University Technology: 
Nature Science Edition, 2012, 37: 294-299 (in Chinese)

33. Shang H, Shi J C, Li J, Liu Y, Zhang W H. Reactor design of microwave assisted demetallization of heavy crude oil. Chemical Engineering Transactions, 2014, 39: 511-516

34. Zhang X, Hayward D O, Mingos D M P. Effects of microwave dielectric heating on heterogeneous catalysis. Catalysis Letters, 2003, 88(1/2): 33-38

35. Chemat F, Esveld D C, Poux M, Di-Martino J L. Role of selective heating in the microwave activation of heterogeneous catalysis reactions using a continuous microwave reactor. Journal of Microwave Power and Electromagnetic Energy, 1998, 33(2): 88-94

36. Zhang X, Hayward D O, Lee C, Mingos D M P. Microwave assisted catalytic reduction of sulfur dioxide with methane over $\mathrm{MoS}_{2}$ catalysts. Applied Catalysis B: Environmental, 2001, 33(2): $137-$ 148

37. Zhang X, Hayward D O, Mingos D M P. Dielectric properties of $\mathrm{MoS}_{2}$ and Pt catalysts: Effects of temperature and microwave frequency. Catalysis Letters, 2002, 84(3/4): 225-233

38. Topsøe H, Clausen B S, Massoth F E. Hydrotreating Catalysis. Berlin: Springer-Verlag, 1996, 116-118

39. Borgna A, Hensen E J M, Coulier L, de Croon M H J M, Schouten J C, van Veen J A R, Niemantsverdriet J W. Intrinsic thiophene hydrodesulfurization kinetics of a sulfided $\mathrm{NiMo} / \mathrm{SiO}_{2}$ model catalyst: Volcano-type behavior. Catalysis Letters, 2003, 90(3/4):
117-122

40. Xu C M, Yang C H. Petroleum Refinery Engineering. 4th ed. Beijing: Petroleum Industry Press, 2009, 373-376 (in Chinese)

41. Clark D E, Folz D C, West J K. Processing materials with microwave energy. Materials Science and Engineering A, 2000, 287(2): 153-158

42. Perreux L, Loupy A. A tentative rationalization of microwave effects in organic synthesis according to the reaction medium and mechanistic considerations. Tetrahedron, 2001, 57(45): 9199-9223

43. Tarbuck T L, Mccrea K R, Logan J W, Heiser J L, Bussell M E. Identification of the adsorption mode of thiophene on sulfided Mo catalysts. Journal of Physical Chemistry B, 1998, 102(40): 78457857

44. Mitchell P C H, Green D A, Grimblot J, Payen E, Tomkinson J. Interaction of thiophene with a molybdenum disulfide catalyst: An inelastic neutron scattering study. Physical Chemistry Chemical Physics, 1995, 104: 325-329

45. Zhao L, Chen Y, Gao J, Chen Y. Desulfurization mechanism of FCC gasoline: A review. Frontiers of Chemical Science and Engineering, 2010, 4(3): 314-321

46. Ruette F, Valencia N, Sanchez-delgado R. Molecular analogs of surface species. 2. A theoretical study of molybdenum carbonyl thiophene complexes: Organometallic models for the chemisorption of thiophene. Journal of the American Chemical Society, 1989, 111(1): 40-46 